\title{
Incorporating phenolic compounds opens a new perspective to use zein films as flexible bioactive packaging materials
}

\author{
Iskender Arcan, Ahmet Yemenicioğlu* \\ Department of Food Engineering, Faculty of Engineering, Izmir Institute of Technology, 35430, Gülbahçe Köyü, Urla, İzmir, Turkey
}

\section{A R T I C L E I N F O}

\section{Article history:}

Received 13 September 2010

Accepted 23 November 2010

\section{Keywords:}

Phenolic compounds

Zein

Edible film

Flexible

Antioxidant

Antimicrobial

\begin{abstract}
A B S T R A C T
To eliminate their classical brittleness and flexibility problems zein films were plasticized by incorporation of different phenolic acids (gallic acid (GA), p-hydroxy benzoic acid (HBA) or ferulic acids (FA)) or flavonoids (catechin (CAT), flavone (FLA) or quercetin (QU)). The use of GA, CAT, FA and HBA at $3 \mathrm{mg} / \mathrm{cm}^{2}$ eliminated the brittleness of films and gave highly flexible films showing elongations between $135 \%$ and $189 \%$, while FLA and QU caused no considerable effect on film elongation. The films containing FA and HBA showed extreme swelling and lost their structural integrity when hydrated in distilled water. In contrast, CAT and GA containing films maintained their integrity following hydration. Most of the GA (up to 93\%) and a considerable portion of CAT (up to $60 \%$ ) in the films existed in soluble form. Therefore, the films showed antioxidant and/or antimicrobial activity. The TEACs of soluble phenolic compounds in $3 \mathrm{mg} / \mathrm{cm}^{2}$ CAT and GA containing films were 21.0 and $86.2 \mu \mathrm{mol}$ trolox $/ \mathrm{cm}^{2}$, respectively. The GA containing films showed antimicrobial activity on Listeria monocytogenes and Campylobacter jejuni, while CAT showed no antimicrobial activity on these bacteria at the studied concentration. This work opens a new perspective for using zein in flexible bioactive packaging. (C) 2010 Elsevier Ltd. All rights reserved.
\end{abstract}

\section{Introduction}

Due to increased health concerns and environmental problems caused by synthetic plastics, extensive studies are conducted to develop edible and environmentally friendly biodegradable packaging materials from natural polymers. Zein, a water insoluble hydrophobic storage protein found in corn and maize, attracts a particular interest as a biopolymer since it has good film forming properties, biodegradability and biocompatibility, and it is the major co-product of the oil industry and rapidly growing bioethanol industry (Selling, Woods, Sessa, \& Biswas, 2008; Shukla \& Cheryan, 2001; Wang et al., 2007; Zhang, Luo, \& Wang, 2011). In foods, zein is applied mainly as a coating material for candies, fresh and dried fruits and nuts and used as an ingredient in chewing gum production (Bai, Alleyne, Hagenmaier, Mattheis, \& Baldwin, 2003; Lai \& Padua, 1997; Shukla \& Cheryan, 2001). Recently, a particular interest has also been focused on use of pre-cast free standing films of zein in modified atmosphere packaging (Rakotonirainy, Wang, \& Padua, 2001) and active food packaging by incorporation of different natural or chemical preservatives (Dawson, Hoffman, \& Han, 2000; Gucbilmez, Yemenicioglu, \& Arslanoglu, 2007; Herald, Hachmeister, Huang, \& Bowers, 1996; Hoffman, Han, \& Dawson, 2001; Janes, Kooshesh, \& Johnson, 2002; Mecitoglu et al., 2006; Padgett, Han, \& Dawson, 1998; Rakotonirainy et al., 2001; Teerakarn, Hirt, Acton, Rieck, \& Dawson, 2002). Although

\footnotetext{
* Corresponding author. Tel.: +90 232 7506292; fax: +90 2327506196. E-mail address: ahmetyemenicioglu@iyte.edu.tr (A. Yemenicioğlu).
}

it has excellent film forming and gas barrier properties, the classical brittleness, and flexibility problems of zein films is a great limitation for their use as a free standing film and more widespread application as a coating material. Many studies have been conducted to plasticize zein films and improve their flexibility and mechanical properties by addition of different ingredients such as organic acids, sugars, alcohols, fatty acids and different synthetic polymers, cross-linkers or plasticizers (Ghanbarzadeh et al., 2006; Kim, Sessa, \& Lawton, 2004; Lai \& Padua, 1997; Lawton, 2004; Sessa, Mohamed, \& Byars, 2008; Woods, Selling, \& Cooke, 2009). However, none of these studies provided an effective solution to flexibility and brittleness problems by use of natural bioactive compounds. Phenolic compounds are among the most potent and abundant bioactive compounds which can easily be obtained from different plant materials, agro-industrial wastes, and byproducts (Ali et al., 2008; Anastasiadi, Chorianopoulos, Nychas, \& Haroutounian, 2009; Bonilla, Mayen, Merida, \& Medina, 1999; Hassan \& Swet Fan, 2005; Liu, Qiu, Ding, \& Yao, 2008). The use of natural phenolic compounds in food packaging is particularly encouraged since they improve food oxidative and microbial status and show many different benefits on human health (Coma, 2008; Crespy \& Williamson, 2004). The molecular weight and structure of phenolic compounds can show a great variation and they may contain different numbers of hydroxyl groups capable to form $\mathrm{H}$-bonding with peptide carbonyl groups of proteins (Damodaran, 1996). Most plasticizers owe their positive effects on film flexibility to their hydroxyl groups which form hydrogen bonds with polymers and increase the free volume of film matrix (Sothornvit \& Krochta, 2005). Therefore, in this study, for the first time in the literature, different 
phenolic acids and flavonoids were employed to eliminate the classical brittleness problem of zein films and improve their flexibility and bioactive properties. This work aims in making a contribution to develop novel flexible edible packaging materials having bioactive properties.

\section{Materials and methods}

\subsection{Materials}

Zein, (+)-catechin and gallic acid were from Sigma Chem Co. (St. Louis, MO, USA). All other chemicals were of reagent grade. Campylobacter jejuni isolated from broiler chicken carcass was kindly provided by Prof. Dr. Halil İbrahim Atabay from microbiology laboratories in Department of Food Engineering at Izmir Institute of Technology, Turkey.

\subsection{Film making}

Zein films were produced as described in Padgett et al. (1998). Briefly, $1.4 \mathrm{~g}$ corn zein was dissolved with $8.1 \mathrm{ml}$ of ethanol (96\%) by mixing slowly with a magnetic stirrer for $25 \mathrm{~min} .0 .4 \mathrm{ml}$ glycerol was then added to the medium and the temperature of the mixture was increased until it started to boil. The mixing was then ceased and the film solution was boiled for $5 \mathrm{~min}$. After cooling to room temperature, different phenolic compounds (catechin, gallic acid, ferulic acid, flavone, quercetin or hydroxy benzoic acid) were added into film forming solutions to obtain $0.75,1.5,2.25,3.0,4.5$ or $6.0 \mathrm{mg}$ phenolic compound per $\mathrm{cm}^{2}$ of dried films. The mixtures were then homogenized (Heidolph, Germany, rotor $\Phi=6.6 \mathrm{~mm}$ tip) at $10,000 \mathrm{rpm}$ for $4 \mathrm{~min}$ and cast into glass templates $(\mathrm{W} \times \mathrm{L} \times \mathrm{H}$ : $8.5 \times 8.5 \times 0.4 \mathrm{~cm}$ ). For films used in mechanical testing, the drying was conducted at $25{ }^{\circ} \mathrm{C}$ and $50 \%$ RH for 19 h by using a controlled test cabinet (TK 120, Nüve, Turkey). The films used in other tests were dried at the same temperature for the same time in a standard incubator without moisture control.

\subsection{Mechanical properties of films}

Tensile strength, elongation at break, and Young's modulus were determined using a Texture Analyser TA-XT2 (Stable Microsystems, Godalming, UK) according to ASTM Standard Method D 882-02 (ASTM, 2002). Films were cut into $5 \mathrm{~mm}$ wide and $80 \mathrm{~mm}$ length strips. Initial grip distance was $50 \mathrm{~mm}$ and crosshead speed was $50 \mathrm{~mm} / \mathrm{min}$. At least seven replicates of each film were tested.

\subsection{Soluble phenolic content of films}

The soluble phenolic content of films was determined by release tests conducted in distilled water at $4{ }^{\circ} \mathrm{C}$ in shaken $(80 \mathrm{rpm})$ Petri dishes. The tests last for 13 days, until reaching of the equilibrium or until an insignificant increase occurred in phenolic concentration by time. For sampling, $300 \mu \mathrm{l}$ sample was taken at different time periods and assayed for phenolic content. The phenolic acids and flavonoids were determined spectrophotometrically according to the FolinChiocalteu method of Singleton and Rossi (1965) and the aluminium chloride colorimetric method given by Zhishen, Mengcheng \& Jianming (1999), respectively. The calibration curves were prepared by using each of the different phenolic compounds indicated in the study. Average of three measurements was used in calculations.

\subsection{Soluble and bound antioxidant capacity of films}

Soluble antioxidant capacity of films was based on free radical scavenging capacity of their total released phenolic content. The trolox equivalent antioxidant capacity (TEAC) of different phenolic com- pounds was determined by area under the curve (AUC) method using ABTS free radical (Re et al., 1999). This method is based on monitoring the percent inhibition of blue colored ABTS free radical from its decolorization by the antioxidant with a spectrophotometer at $734 \mathrm{~nm}$ (test periods: $1,3,6,9,12$, and $15 \mathrm{~min}$ ). The results were expressed as $\mu \mathrm{mol}$ trolox released per $\mathrm{cm}^{2}$ of the films ( $\mu \mathrm{mol}$ trolox $/ \mathrm{cm}^{2}$ ). Average of three measurements was used in calculations.

Bound antioxidant capacity of films obtained from 13 day release tests was determined by modifying the method described by Gucbilmez et al. (2007). Briefly, the films were washed two times with $100 \mathrm{ml}$ of deionized water $(2 \times 50 \mathrm{ml})$ for $60 \mathrm{~min}$ by shaking to remove residual soluble phenolic compounds remained in films following release tests. Three pieces were cut from the films and placed into Petri dishes containing $50 \mathrm{ml}$ of ABTS free radical solution. The reaction was conducted at $30{ }^{\circ} \mathrm{C}$ by shaking at $80 \mathrm{rpm}$ and the percent inhibition of ABTS solution was monitored for $60 \mathrm{~min}$ at $734 \mathrm{~nm}$. The antioxidant capacity was determined for $15 \mathrm{~min}$ inhibition period as $\mu \mathrm{mol}$ trolox $/ \mathrm{cm}^{2}$. Average of three measurements was used in calculations.

\subsection{Antimicrobial activity of films}

The antimicrobial activities of films were tested against Listeria monocytogenes (ATCC 7644) and C. jejuni. Fifteen discs $(1.3 \mathrm{~cm}$ in diameter) were prepared from films by a cork borer under aseptic conditions. During tests, 3 discs were placed carefully onto each Petri dish containing nutrient agar on which inoculated by spreading $0.1 \mathrm{ml}$ inoculum of different microorganisms. The inoculums of microorganisms were prepared in nutrient broth using an overnight culture of L. monocytogenes at aerobic conditions, and $48 \mathrm{~h}$ culture of $C$. jejuni at microaerophilic conditions (microaerophilic conditions were achieved by jars of Anoxomat, Mart Microbiology, Holland). The incubation of both bacteria was conducted at $37^{\circ} \mathrm{C}$. The bacterial counts of inoculums for L. monocytogenes and C. jejuni used in tests were $3.0 \times 10^{9}$ and $6 \times 10^{7} \mathrm{CFU} / \mathrm{ml}$, respectively. The Petri dishes inoculated with L. monocytogenes and C. jejuni and containing film discs were incubated for $48 \mathrm{~h}$ at $37^{\circ} \mathrm{C}$. The diameter of the zones formed was measured by using a caliper. The results were expressed as average zone areas $\left(\mathrm{cm}^{2}\right)$.

\subsection{Scanning electron microscopy (SEM)}

The photographs of film cross sections and film thicknesses were determined by SEM (Philips XL 30S FEG, FEI Company, Netherlands). The films were prepared for SEM by crushing following freezing in liquid nitrogen.

\subsection{Statistical analysis}

Results were analyzed for significance by the Fisher's protected least significant difference method. Differences were considered significant if $P<0.05$.

\section{Results and discussion}

\subsection{Effect of phenolic compounds on mechanical properties of films}

The effects of phenolic compounds on mechanical properties of zein films were investigated by using catechin (CAT), a flavonoid $\left(\mathrm{C}_{6} \mathrm{C}_{3} \mathrm{C}_{6}\right)$ and gallic acid (GA), a phenolic acid $\left(\mathrm{C}_{6} \mathrm{C}_{1}\right)$ as main model phenolic compounds at concentration range between 0.75 and $3.0 \mathrm{mg}$ per $\mathrm{cm}^{2}$ of films (Fig. 1). These compounds were particularly selected due to their good solubility in both water and ethanol, different molecular structures and high number of hydroxyl groups which are necessary to form hydrogen bonds with carbonyl groups of zein and modify the networking and free volume of film matrix. Moreover, CAT and GA were reported to show antioxidant and 
A<smiles>O=C(O)c1cc(O)c(O)c(O)c1</smiles>

D<smiles>O=c1cc(-c2ccccc2)oc2ccccc12</smiles>

B<smiles>O=C(O)c1ccc(O)cc1</smiles>

C<smiles>COc1cc(/C=C/C(=O)O)ccc1O</smiles>

E<smiles>Oc1cc(O)c2c(c1)O[C@H](c1ccc(O)c(O)c1)[C@H](O)C2</smiles>

$\mathbf{F}$<smiles>O=c1c(O)c(-c2ccc(O)c(O)c2)oc2cc(O)cc(O)c12</smiles>

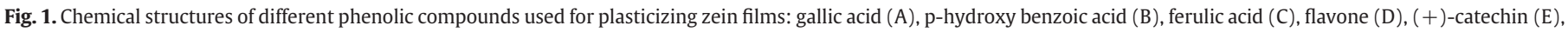
and quercetin $(\mathrm{F})$.

antimicrobial activity to improve bioactive properties of films (Anastasiadi, Pratsinis, Kletsas, Skaltsounis, \& Haroutounian, 2010; Saucier \& Waterhouse, 1999; Yilmaz \& Toledo, 2004).

The average thicknesses of control films and films containing CAT or GA at different concentrations $\left(0.75,1.5,2.25\right.$ or $\left.3 \mathrm{mg} / \mathrm{cm}^{2}\right)$ were $131.8 \pm 2.0,127.1 \pm 5.3$ and $129.0 \pm 12.2 \mu \mathrm{m}$, respectively. Thus, the addition of CAT or GA did not affect the film thickness considerably. The glycerol used in all zein films did not show a considerable plasticizing effect, but it reduced the brittleness of zein films and enable conducting mechanical tests for highly brittle control films. In contrast, addition of CAT or GA into zein films increased the flexibility of films and this increased the elongation of films in a concentration dependent manner (Fig. 2). The GA is a particularly effective plasticizer for zein since it caused considerably higher film elongation than CAT at low phenolic concentrations. The effect of CAT and GA on tensile strength and Young's modulus of zein films was also given in Fig. 3. The tensile strength and Young's modulus of zein films reduced as phenolic concentration in the films was increased. However, CAT containing films showed higher tensile strength and Young's modulus values than GA containing films at all phenolic concentrations. No mechanical tests were conducted above $3 \mathrm{mg} / \mathrm{cm}^{2}$, since such films became highly sticky, and hard to peel and handle following drying. However, it's worthy to note that the flexibility of films continue to increase as CAT and GA increased as much as $6 \mathrm{mg} / \mathrm{cm}^{2}$.

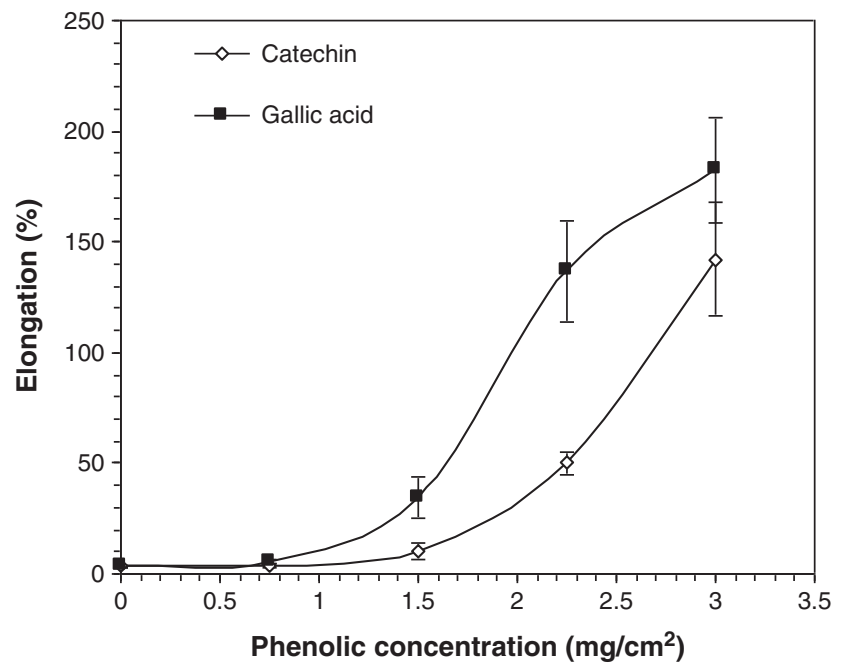

Fig. 2. Effects of catechin and gallic acid concentrations on elongation of zein films.
The effects of different flavonoids, flavone (FLA) and quercetin (QU), and fenolic acids, ferulic acid (FA) and hydroxyl benzoic acid (HBA), on mechanical properties of zein films were also tested at $3 \mathrm{mg} / \mathrm{cm}^{2}$ concentration (Table 1 ). The thicknesses of films containing different phenolic compounds did not vary considerably with the exception of FLA containing films which were slightly thicker than the others. The elongation, tensile strength and Young's modulus values of FA and HBA containing films were not statistically significantly different from those of GA containing films $(P>0.05)$. Moreover, similar to GA containing films, FA and HBA containing films showed lower tensile strength and Young's modulus than CAT containing films. The elongation of HBA containing films was also significantly higher than that of CAT containing films, but FA containing films showed similar elongation with CAT containing films. On the other hand, during hydration tests conducted in distilled water, the films containing FA and HBA showed rapid swelling and lost their structural integrity (their surface become quite rough), while CAT and GA containing films maintained their structural integrity and smooth surface even after hydration. It is clear that the molecular properties of phenolic compounds affected the film morphology and strength of film matrix considerably. It seems that the extensive $\mathrm{H}$ bonding of CAT or GA molecules which contained higher number of $\mathrm{OH}$ groups than FA and HBA created a stronger network within film matrix and this prevented loss of film structural integrity following hydration. The

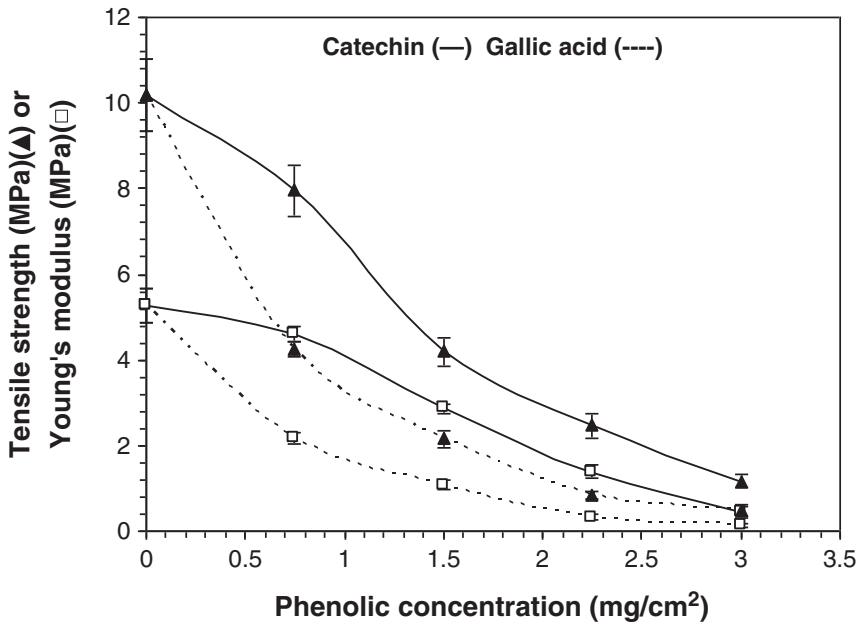

Fig. 3. Effects of catechin and gallic acid concentrations on tensile strength and Young's modulus of zein films. 
Table 1

Mechanical properties of zein films plasticized with different phenolic compounds (phenolic concentration of films: $3 \mathrm{mg} / \mathrm{cm}^{2}$ )

\begin{tabular}{|c|c|c|c|c|}
\hline Phenolics & Tensile strength (MPa) & Elongation (\%) & Young's modulus (MPa) & Film thickness $(\mu \mathrm{m})$ \\
\hline Control & $10.19 \pm 0.83 a^{a}$ & $3.34 \pm 0.66 c$ & $5.28 \pm 0.39 a$ & $131.8 \pm 2.0$ \\
\hline CAT & $1.16 \pm 0.16 \mathrm{~d}$ & $142.24 \pm 25.52 b$ & $0.45 \pm 0.14 \mathrm{~d}$ & $132.1 \pm 3.5$ \\
\hline GA & $0.48 \pm 0.12 \mathrm{e}$ & $182.41 \pm 23.61 \mathrm{a}$ & $0.12 \pm 0.04 \mathrm{e}$ & $116.9 \pm 0.8$ \\
\hline HBA & $0.45 \pm 0.02 \mathrm{e}$ & $188.64 \pm 25.10 \mathrm{a}$ & $0.12 \pm 0.01 \mathrm{e}$ & $120.1 \pm 0.7$ \\
\hline FA & $0.70 \pm 0.05 \mathrm{e}$ & $135.05 \pm 50.21 \mathrm{ab}$ & $0.24 \pm 0.03 \mathrm{de}$ & $123.9 \pm 0.5$ \\
\hline FLA & $6.70 \pm 0.31 b$ & $2.21 \pm 0.26 c$ & $3.98 \pm 0.15 c$ & $143.4 \pm 1.4$ \\
\hline QU & $5.28 \pm 0.29 c$ & $1.23 \pm 0.18 c$ & $4.74 \pm 0.15 b$ & $125.9 \pm 3.5$ \\
\hline
\end{tabular}

a Different letters in each column show significant difference at $P<0.05$.

films containing flavonoids, FLA and QU, on the other hand, showed completely different mechanical properties than using CAT and phenolic acids. The FLA was selected particularly to see plasticizing effect of a phenolic compound lacking OH groups, while QU was selected due to its same number of OH groups with CAT. However, these flavonoids did not act as effective plasticizers and caused statistically insignificant changes in elongation of films $(P>0.05)$. Moreover, FLA and QU gave most identical TS and EM values with the controls. The lack of any considerable plasticizing effect for FLA was expected, but the ineffectiveness of QU should be related with its insolubility within the films. Both FLA and QU showed limited solubility in ethanol and formed tiny crystals and granules within the films after drying.

The solution of the mechanism of mechanical changes by addition of different phenolic compounds needs some more detailed analysis of zein film structure. The characteristic film structure of zein consists of a meshwork composed of doughnut structures formed by asymmetric rods joined to each other (Guo, Liu, An, Li, \& Hu, 2005). It is the hydrophobic interactions that keep the zein rots together and maintain film integrity (Guo et al., 2005), but these interactions are also responsible for the brittleness and lack of flexibility in zein films. The increased flexibility of zein films by the addition of phenolic compounds seemed to be occurred by binding of phenolic compounds on zein protein's surface and resulting increase of free volume in film matrix. The hydrophilic groups of phenolic compounds also decreased the hydrophobic interaction among zein molecules and this contributed to their increased mobility that eliminated brittleness and flexibility problems of films.

In the literature, reports about plasticizing effect of pure phenolic acids and flavonoids on protein based films scarce. In fact, it is only Ou, Wang, Tang, Huang, and Jackson (2005) who reported a limited increase in elongation of soy protein films by addition of ferulic acid. In contrast, Emmambux, Stading, and Taylor (2004) incorporated condensed tannins like tannic acid (TA) into films from sorghum kafirin, a zein like prolamin, reported an antiplasticizing effect of this phenolic compound after determining a reduced elongation, but increased tensile strength and Young's modulus of the films. The antiplasticizing effect could be due to molecular properties of TA, since this phenolic compound contains too many hydroxyl groups and it binds proteins very tightly to reduce their mobility within the film matrix. Emmambux et al. (2004) applied extensive heating (at 55 to $75^{\circ} \mathrm{C}$ range) to zein-tannic acid mixtures during both film preparation and drying. Thus, it is also possible that the antiplasticizing effect was due to oxidation of TA which could cause covalent crosslinking of proteins (Thalmann \& Lötzbeyer, 2002). Another study which employed a pure phenolic compound during edible film production came from Ku, Hong, and Song (2008), but these workers incorporated the phenolic compound catechin into a carbohydrate film from agar extracted from Gelidium corneum and did not determine any plasticizing effect of catechin. On the other hand, there are many different studies in the literature related to plasticization of zein films with different compounds. For example, Lawton (2004) obtained cast zein films and tested different plasticizers including triethylene glycol, dibuthyl tartrate, levulinic acid, polyethylene glycerol 300, glycerol and oleic acid. This worker did not determine any plasticizing effect of glycerol and oleic acid, but other compounds showed considerable plasticizing effect when films were stored 1 week at relative humidity values exceeding 60\%. However, Lawton (2004) attributed the obtained plasticizing effect to water molecules absorbed by the films during storage, but not to the applied plasticizers. On the other hand, although oleic acid was not a good plasticizer for cast zein films, it showed some plasticizing effect (with $12 \%$ elongation) when films were obtained from stretched resins formed by zein-oleic acid emulsions (Lai \& Padua, 1997). Kim et al. (2004) reduced the brittleness of zein films and increased their tensile strengths by using some chemical crosslinkers such as 1-[3-dimethylaminopropyl]-3-ethylcarbodiimide hydrochloride and $\mathrm{N}$-hydroxysuccinimide, but this process did not increase the film elongation considerably (increased only from 2.23 to $3.6 \%$ ). Sessa et al. (2008) improved tensile strength, elongation and Young's modulus of zein films by glutaraldehyde crosslinking, but the films lost their edible nature due to toxicity of this compound.

\subsection{Soluble catechin content and antioxidant potential of films}

The release profiles of GA and CAT from zein films incubated at $4{ }^{\circ} \mathrm{C}$ were given in Fig. 4 . In 1.5 and $3.0 \mathrm{mg} / \mathrm{cm}^{2}$ phenolic containing films, total GA released was 1.6 and 1.9 fold higher than total CAT released, respectively (Table 2 ). Thus, the average soluble CAT and GA contents were $49 \%$ and $88 \%$ of total CAT and GA incorporated into films, respectively. The TEAC of GA $(34.6 \mu \mathrm{mol}$ trolox/g) is also 2.1 fold higher than that of CAT $(16.1 \mu \mathrm{mol}$ trolox/g). Therefore, the TEACs of total GA released from 1.5 to $3.0 \mathrm{mg} / \mathrm{cm}^{2}$ phenolic containing films were 3.6 and 4.1 fold higher than those of total CAT released from corresponding films, respectively. In both, CAT and GA containing films, the trapped phenolic compounds showed some free radical scavenging activity (bound antioxidant activity). However, for both phenolic compounds the TEAC of bound antioxidant activity changed

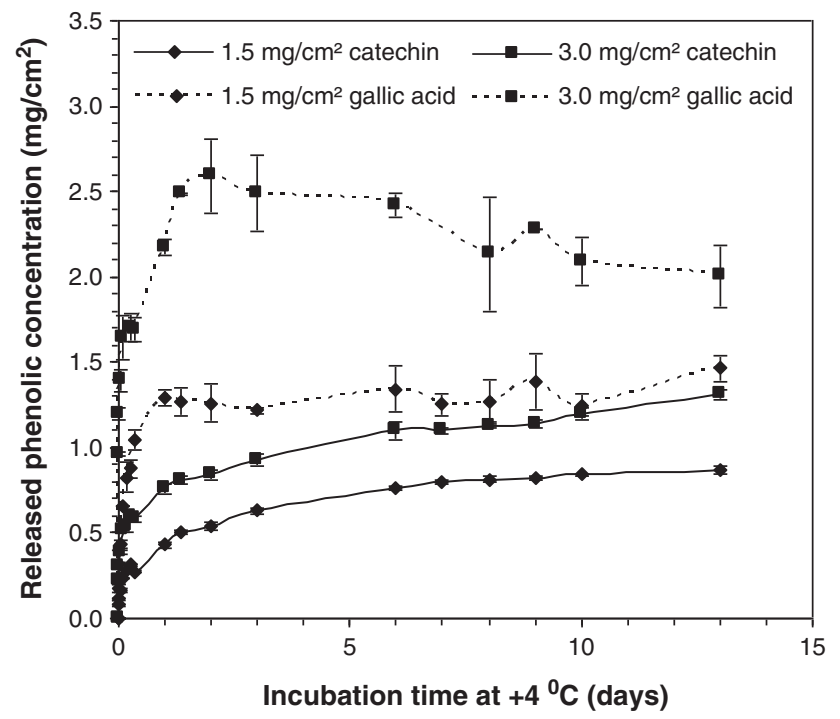

Fig. 4. Release profiles of different phenolic compounds from zein films incubated in distilled water at $4{ }^{\circ} \mathrm{C}$. 
Table 2

Soluble phenolic content and free radical scavenging activity of different zein films.

\begin{tabular}{lllll}
\hline $\begin{array}{l}\text { Phenolics } \\
\left(\mathrm{mg} / \mathrm{cm}^{2}\right)\end{array}$ & $\begin{array}{l}\text { Soluble phenolic } \\
\text { content }\left(\mathrm{mg} / \mathrm{cm}^{2}\right)\end{array}$ & $\begin{array}{l}\text { Soluble TEAC } \\
\left(\mu \mathrm{mol} \text { trolox } / \mathrm{cm}^{2}\right)\end{array}$ & $\begin{array}{l}\text { Bound TEAC } \\
\left(\mu \mathrm{mol} \mathrm{trolox} / \mathrm{cm}^{2}\right)\end{array}$ \\
\hline CAT & GA & & & \\
\hline 1.5 & - & $0.9 \pm 0.03(58 \%)^{\mathrm{a}}$ & $14.0 \pm 0.5$ & $0.18 \pm 0.04$ \\
3.0 & - & $1.3 \pm 0.03(43 \%)$ & $21.0 \pm 0.5$ & $0.41 \pm 0.04$ \\
4.5 & - & $2.0 \pm 0.02(44 \%)$ & $32.0 \pm 0.3$ & $-\mathrm{b}$ \\
6.0 & - & $3.1 \pm 0.08(52 \%)$ & $49.0 \pm 1.3$ & - \\
- & 1.5 & $1.4 \pm 0.08(93 \%)$ & $50.5 \pm 2.8$ & $1.32 \pm 0.02$ \\
- & 3.0 & $2.5 \pm 0.22(83 \%)$ & $86.2 \pm 7.6$ & $1.49 \pm 0.00$ \\
\hline
\end{tabular}

aPercentage of soluble phenolic content in the films; ${ }^{b}$ not determined.

between 1.3 and $2.6 \%$ of soluble TEAC. Although, greater amounts of CAT than GA trapped within zein films, the GA containing films showed 3.5 to 7 fold higher bound TEAC than the CAT containing films. The higher bound antioxidant activity of GA containing films should be related with higher free radical scavenging activity of GA than CAT and morphological properties of GA containing films which enable better contact of bound GA with free radical solution. The use of antioxidant phenolic compounds in edible films is quite beneficial to improve oxidative stability of packed foods. For example, Ku et al. (2008) successfully controlled oxidative changes in sausages packed with agar based films containing catechin. Moreover, the GA and CAT consumed with food could also contribute to human health since these potent antioxidants have protective effects against cardiovascular diseases and anticancerogenic activity (Madlener et al., 2007; Shahrzad, Aoyagi, Winter, Koyama, \& Bitsch, 2001; Yilmaz \& Toledo, 2004).

\subsection{Antimicrobial potential of films}

The films containing $3 \mathrm{mg} / \mathrm{cm}^{2}$ CAT did not show any antimicrobial activity on $L$. monocytogenes and $C$. jejuni used in microbial tests. In contrast, films containing GA at the same concentration showed good antimicrobial activity on both $L$. monocytogenes and $C$. jejuni and formed $2.07 \pm 0.34 \mathrm{~cm}^{2}$ and $1.66 \pm 0.36 \mathrm{~cm}^{2}$ clear zones around tested discs, respectively. The effectiveness of GA on L. monocytogenes and C.
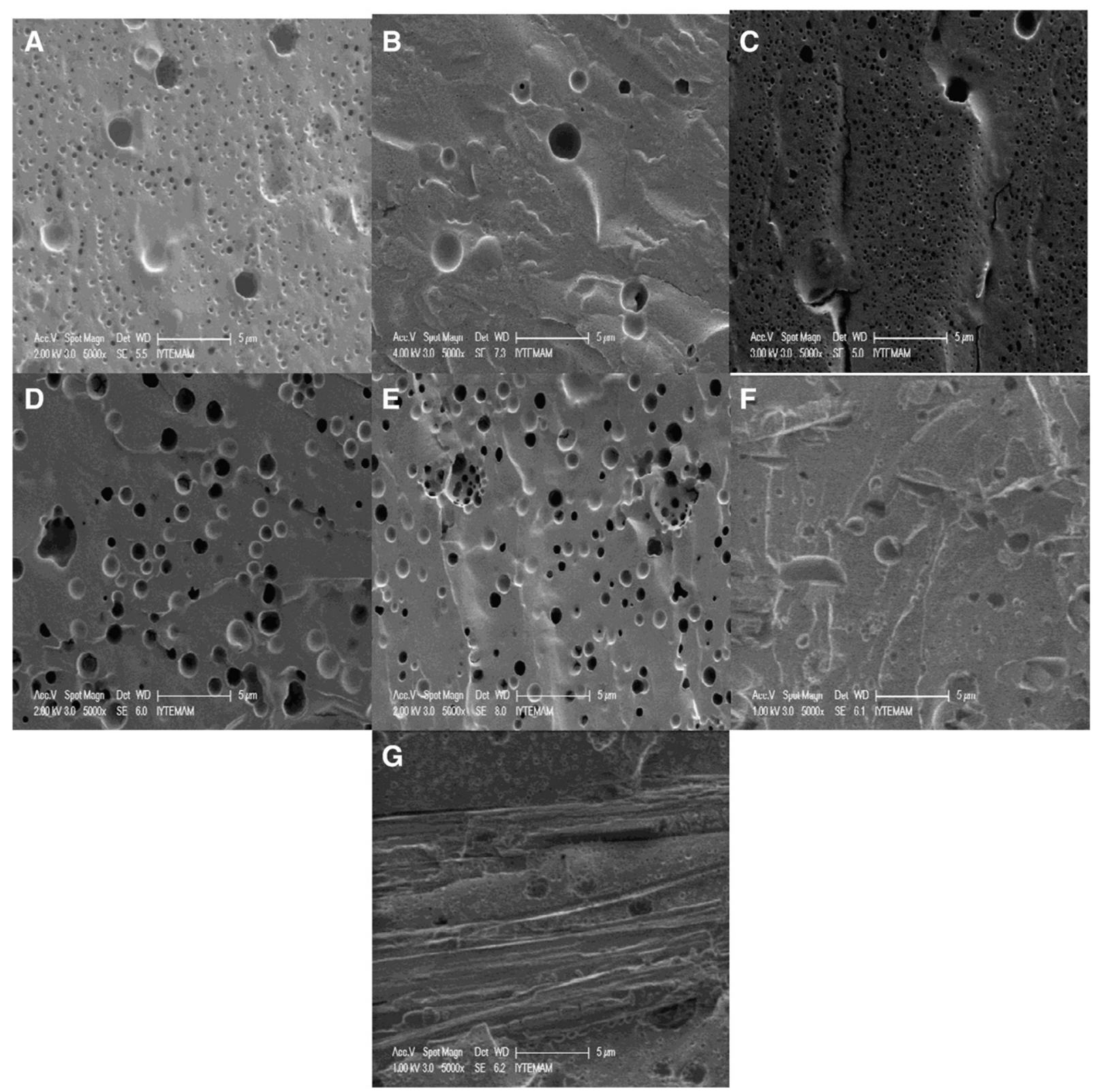

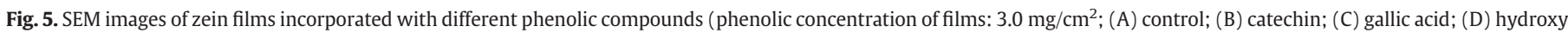
benzoic acid; (E) ferulic acid; (F) quercetin; and (G) flavone). 
jejuni, but lack of antimicrobial activity of CAT on C. jejuni showed parallelism with reports of previous workers who tested solutions of these compounds on indicated bacteria (Ganan, Martinez-Rodriguez, \& Carrascosa, 2009; Vaquero, Alberto, \& de Nadra, 2007). However, our results showing lack of antimicrobial activity of CAT on $L$. monocytogenes contradicted with those of Vaquero et al. (2007) and $\mathrm{Ku}$ et al. (2008) who found this flavonoid effective against this bacteria in agar well diffusion test and in a food packaging application conducted with inoculated sausages, respectively. Due to differences in the antimicrobial test methods, it is hard to compare the effectiveness of CAT concentrations in our study with those of indicated workers. However, it seems that the CAT concentration which gave optimal mechanical properties (elongation over 100\% without formation of sticky film structure) in our study is less than the critical inhibitory concentration necessary to form detectable clear zones during the applied zone inhibition method. Further antimicrobial tests are needed for CAT containing films by using different microbiological methods.

\subsection{SEM images of films}

The SEM images obtained for cross-sections of control films and films containing $3 \mathrm{mg} / \mathrm{cm}^{2}$ of different phenolic compounds were given in Fig. 5A to $\mathrm{G}$. The incorporation of different phenolic compounds caused formation of different film structures. For example, the incorporation of CAT reduced the porosity of films, while incorporation of GA increased film porosity (Fig. 5B and C). This result explained the greater amounts of GA release than the CAT release from zein films. However, the CAT (MW: 290.3) also have greater molecular weight and more $\mathrm{H}$ bonding $-\mathrm{OH}$ groups $(\mathrm{OH})$ than GA (MW: 170.1). Thus, greater trapping of CAT within the films might also be affected from its molecular size which limited its diffusion from the films. The higher porosity of GA containing films than CAT containing films also supported our hypothesis that the high bound antioxidant activity of GA containing films might be due to their greater interaction with the free radical solution. On the other hand, the high number of large pores observed in HBA and FA containing films could be related with rapid swelling and loss of integrity of these films when they were incubated in distilled water (Fig. 5D and E). The SEM photos of FLA and QU containing films also showed the presence of different shapes and forms of aggregates and this supported our observations about solubility problems of these phenolic compounds in films (Fig. 5F and G).

In conclusion, the incorporation of phenolic compounds such as catechin, gallic acid, p-hydroxy benzoic acid and ferulic acid eliminates the classical brittleness problem of zein films and increases their flexibility considerably. The films containing phenolic compounds have antioxidant and antimicrobial potential since a considerable portion of the phenolic compound in the films exists in soluble form. Results of this work clearly showed the good potential of using phenolic compounds in developing flexible bioactive packaging materials from zein, a biopolymer which is expected to be produced in huge amounts in a near future as a byproduct of rapidly developing bioethanol industry. Further studies are now continuing in our laboratories to test the active potential of these films in real packaging applications and optimize their mechanical properties accordingly.

\section{Acknowledgements}

This work (No. 108M353) was funded by The Scientific and Technical Research Council of Turkey (TÜBITAK). We appreciate the IYTE Biotechnology and Bioengineering Central Research Laboratories (BIYOMER) for providing laboratory facilities for microbiological analysis. The SEM analysis of the films was conducted in Material Research Center (IYTEMAM) at Izmir Institute of Technology.

\section{References}

Ali, S. S., Kasoju, N., Luthra, A., Singh, A., Sharanabasava, H., Sahu, A., et al. (2008). Indian medicinal herbs as sources of antioxidants. Food Research International, 41(1), $1-15$.

Anastasiadi, M., Chorianopoulos, N. G., Nychas, G. -J. E., \& Haroutounian, S. A. (2009). Antilisterial activities of polyphenol-rich extracts of grapes and vinification byproducts. Journal of Agricultural and Food Chemistry, 57(2), 457-463.

Anastasiadi, M., Pratsinis, H., Kletsas, D., Skaltsounis, A. -L., \& Haroutounian, S. A. (2010). Bioactive non-coloured polyphenols content of grapes, wines and vinification byproducts: Evaluation of the antioxidant activities of their extracts. Food Research International, 43(3), 805-813.

ASTM (2002). Standard test method for tensile properties of thin plastic sheetingD882-02. ASTM, Annual Book of American Standard Testing Methods. Philadelphia, PA.

Bai, J., Alleyne, V., Hagenmaier, R. D., Mattheis, J. P., \& Baldwin, E. A. (2003). Formulation of zein coatings for apples (Malus domestica Borkh). Postharvest Biology and Technology, 28(2), 259-268.

Bonilla, F., Mayen, M., Merida, J., \& Medina, M. (1999). Extraction of phenolic compounds from red grape marc for use as food lipid antioxidants. Food Chemistry, 66(2), 209-215.

Coma, V. (2008). Bioactive packaging technologies for extended shelf life of meat-based products. Meat Science, 78(1-2), 90-103.

Crespy, V., \& Williamson, G. (2004). A review of the health effects of green tea catechins in in vivo animal models. The Journal of Nutrition, 134(12 Suppl), 3431S-3440S.

Damodaran, S. (1996). Amino acids, peptides and proteins. Food Chemistry, 347.

Dawson, P., Hoffman, K., \& Han, I. (2000). Biocide-impregnated food films to inhibit food pathogens. Ann Arbor: Nsf International.

Emmambux, M. N., Stading, M., \& Taylor, J. R. N. (2004). Sorghum kafirin film property modification with hydrolysable and concensed tannins. Journal of Cereal Science, 40, $127-135$.

Ganan, M., Martinez-Rodriguez, A. J., \& Carrascosa, A. V. (2009). Antimicrobial activity of phenolic compounds of wine against Campylobacter jejuni. Food Control, 20(8), $739-742$.

Ghanbarzadeh, B., Oromiehie, A. R., Musavi, M., D-Jomeh, Z. E., Rad, E. R., \& Milani, W. (2006). Effect of plasticizing sugars on rheological and thermal properties of zein resins and mechanical properties of zein films. Food Research International, 39(8), $882-890$.

Gucbilmez, C. M., Yemenicioglu, A., \& Arslanoglu, A. (2007). Antimicrobial and antioxidant activity of edible zein films incorporated with lysozyme, albumin proteins and disodium EDTA. Food Research International, 40(1), 80-91.

Guo, Y., Liu, Z., An, H., Li, M., \& Hu, J. (2005). Nano-structure and properties of maize zein studied by atomic force microscopy. Journal of Cereal Science, 41(3), 277-281.

Hassan, O., \& Swet Fan, L. (2005). The anti-oxidation potential of polyphenol extract from cocoa leaves on mechanically deboned chicken meat (MDCM). LWT Food Science and Technology, 38(4), 315-321.

Herald, T. J., Hachmeister, K. A., Huang, S., \& Bowers, J. R. (1996). Corn zein packaging materials for cooked turkey. Journal of Food Science, 61(2), 415-418.

Hoffman, K. L., Han, I. Y., \& Dawson, P. L. (2001). Antimicrobial effects of corn zein films impregnated with nisin, lauric acid, and EDTA. Journal of Food Protection, 64(6), $885-889$.

Janes, M. E., Kooshesh, S., \& Johnson, M. G. (2002). Control of Listeria monocytogenes on the surface of refrigerated, ready-to-eat chicken coated with edible zein film coatings containing nisin and/or calcium propionate. Journal of Food Science, 67(7), $2754-2757$.

Kim, S., Sessa, D. J., \& Lawton, J. W. (2004). Characterization of zein modified with a mild cross-linking agent. Industrial Crops and Products, 20(3), 291-300.

Ku, K. J., Hong, Y. H., \& Song, K. B. (2008). Mechanical properties of a Gelidium corneum edible film containing catechin and its application in sausages. Journal of Food Science, 73(3), 217-221.

Lai, H. M., \& Padua, G. W. (1997). Properties and microstructure of plasticized zein films. Cereal Chemistry, 74(6), 771-775.

Lawton, J. W. (2004). Plasticizers for zein: Their effect on tensile properties and water absorption of zein films. Cereal Chemistry, 81(1), 1-5.

Liu, H., Qiu, N., Ding, H., \& Yao, R. (2008). Polyphenols contents and antioxidant capacity of 68 Chinese herbals suitable for medical or food uses. Food Research International, 41(4), 363-370.

Mecitoglu, C., Yemenicioglu, A., Arslanoglu, A., Elmaci, Z. S., Korel, F., \& Cetin, A. E. (2006). Incorporation of partially purified hen egg white lysozyme into zein films for antimicrobial food packaging. Food Research International, 39(1), 12-21.

Madlener, S., Illmer, C., Horvath, Z., Saiko, P., Losert, A., Herbacek, I., et al. (2007). Gallic acid inhibits ribonucleotide reductase and cyclooxygenases in human HL-60 promyelocytic leukemia cells. Cancer Letters, 245, 156-162.

Ou, S., Wang, Y., Tang, S., Huang, S., \& Jackson, M. G. (2005). Role of ferulic acid in preparing edible films form soy protein isolate. Journal of Food Engineering, 70, $205-210$.

Padgett, T., Han, I. Y., \& Dawson, P. L. (1998). Incorporation of food-grade antimicrobial compounds into biodegradable packaging films. Journal of Food Protection, 61(10), $1330-1335$.

Rakotonirainy, A. M., Wang, Q., \& Padua, G. W. (2001). Evaluation of zein films as modified atmosphere packaging for fresh broccoli. Journal of Food Science, 66(8), 1108-1111.

Re, R., Pellegrini, N., Proteggente, A., Pannala, A., Yang, M., \& Rice-Evans, C. (1999). Antioxidant activity applying an improved ABTS radical cation decolorization assay. Free Radical Biology \& Medicine, 26(9-10), 1231-1237.

Saucier, C. T., \& Waterhouse, A. L. (1999). Synergetic activity of catechin and other antioxidants. Journal of Agricultural and Food Chemistry, 47(11), 4491-4494. 
Selling, G. W., Woods, K. K., Sessa, D., \& Biswas, A. (2008). Electrospun zein fibers using glutaraldehyde as the crosslinking reagent: Effect of time and temperature. Macromolecular Chemistry and Physics, 209(10), 1003-1011.

Sessa, D. J., Mohamed, A., \& Byars, J. A. (2008). Chemistry and physical properties of melt-processed and solution-cross-linked corn zein. Journal of Agricultural and Food Chemistry, 56(16), 7067-7075.

Shahrzad, S., Aoyagi, K., Winter, A., Koyama, A., \& Bitsch, I. (2001). Pharmacokinetics of gallic acid and its relative bioevailability from tea in healthy humans. The Journal of Nutrition, 131, 1207-1210.

Shukla, R., \& Cheryan, M. (2001). Zein: The industrial protein from corn. Industrial Crops and Products, 13(3), 171-192.

Singleton, V. L., \& Rossi, J. A., Jr. (1965). Colorimetry of total phenolics with phosphomolybdic-phosphotungstic acid reagents. Am. J. Enol. Vitic., 16(3), $144-158$.

Sothornvit, R., \& Krochta, J. M. (2005). Plasticizers in edible films and coatings. In H. H. Jung (Ed.), Innovations in food packaging (pp. 403-433). London: Academic Press.

Teerakarn, A., Hirt, D. E., Acton, J. C., Rieck, J. R., \& Dawson, P. L. (2002). Nisin diffusion in protein films: Effects of film type and temperature. Journal of Food Science, 67(8), 3019-3025.
Thalmann, C. R., \& Lötzbeyer, T. (2002). Enzymatic cross-linking of proteins with tyrosinase. European Food Research and Technology, 214, 276-281.

Vaquero, M. J. R., Alberto, M. R., \& de Nadra, M. C. M. (2007). Influence of phenolic compounds from wines on the growth of Listeria monocytogenes. Food Control, 18(5), 587-593.

Wang, H. -J., Gong, S. -J., Lin, Z. -X., Fu, J. -X., Xue, S. -T., Huang, J. -C., et al. (2007). In vivo biocompatibility and mechanical properties of porous zein scaffolds. Biomaterials, 28(27), 3952-3964.

Woods, K. K. Selling, G. W., \& Cooke, P. H. (2009). Compatible blends of zein and polyvinylpyrrolidone. Journal of Polymers and the Environment, 17(2), 115-122.

Yilmaz, Y., \& Toledo, R. T. (2004). Health aspects of functional grape seed constituents. Trends in Food Science and Technology, 15(9), 422-433.

Zhang, B., Luo, Y., \& Wang, Q. (2011). Effect of acid and base treatments on structural, rheological, and antioxidant properties of [alpha]-zein. Food Chemistry, 124(1), 210-220.

Zhishen, J., Mengcheng, T., \& Jianming, W. (1999). The determination of flavonoid contents in mulberry and their scavenging effects on superoxide radicals. Food Chemistry, 64(4), 555-559. 